\title{
Advanced Technology in the Management of Diabetes: Which Comes First-Continuous Glucose Monitor or Insulin Pump?
}

\author{
Christopher T. Martin ${ }^{1} \cdot$ Amy B. Criego ${ }^{2} \cdot$ Anders L. Carlson $^{3} \cdot$ Richard M. Bergenstal $^{4}$
}

Published online: 27 June 2019

(C) The Author(s) 2019

\begin{abstract}
Purpose of Review In this article, we consider advanced technologies for the management of diabetes. Recent Findings Specifically, we pose the question of which should come first: an insulin pump (CSII) or a continuous glucose monitor (CGM)? Historical perspective on both insulin delivery and glucose measurement is provided. Recently published clinical trials are reviewed. Practical issues including quality of life, patient education, and out-of-pocket cost are discussed. Summary Based on available evidence and clinical experience, we favor CGM as a first-line technology recommendation for the treatment of type 1 diabetes (T1D).
\end{abstract}

Keywords Continuous glucose monitor · Insulin pump $\cdot$ Diabetes $\cdot$ Hypoglycemia $\cdot$ Time in range $\cdot$ Hemoglobin A1C

$\begin{array}{ll}\text { Abbreviations } \\ \text { SMBG } & \text { Self-monitoring of blood glucose } \\ \text { CGM } & \text { Continuous glucose monitor } \\ \text { DM } & \text { Diabetes mellitus } \\ \text { T1D } & \text { Type 1 diabetes } \\ \text { T2D } & \text { Type } 2 \text { diabetes } \\ \text { \%CV } & \text { Percent coefficient of variation } \\ \text { SD } & \text { Standard deviation } \\ \text { GMI } & \text { Glucose Management Indicator } \\ \text { TIR } & \text { Time in range } \\ \text { MDI } & \text { Multiple daily injections }\end{array}$

This article is part of the Topical Collection on Therapies and New Technologies in the Treatment of Diabetes

Electronic supplementary material The online version of this article (https://doi.org/10.1007/s11892-019-1177-7) contains supplementary material, which is available to authorized users.

Christopher T. Martin

christopher.martin@allina.com

Amy B. Criego

amy.criego@parknicollet.com

\author{
Anders L. Carlson \\ anders.1.carlson@healthpartners.com \\ Richard M. Bergenstal \\ richard.bergenstal@parknicollet.com
}

$\begin{array}{ll}\text { CSII } & \text { Continuous subcutaneous insulin infusion } \\ \text { ISF } & \text { Interstitial fluid } \\ \text { HbA1c } & \text { Glycosylated hemoglobin }\end{array}$

\section{Introduction}

The first commercially available insulin preparations varied in potency up to $25 \%$, contained impurities associated with allergic reactions, and necessitated several injections daily due to non-physiologic pharmacokinetics [1]. The introduction of
1 Allina Health, West Metro Endocrinology, Edina, MN 55435, USA

2 International Diabetes Center, Park Nicollet Pediatric Endocrine, Minneapolis, MN 55416, USA

3 International Diabetes Center, HealthPartners Endocrinology, Minneapolis, MN 55416, USA

4 International Diabetes Center, HealthPartners Institutes, Minneapolis, MN 55416, USA 
insulin analogues, with both rapid and prolonged durations of action, has been shown to reduce hypoglycemia and offer improved flexibility to patients [2]. These newer insulins have allowed for ways to more intensively administer insulin, either as multiple daily injections (MDI) or continuous subcutaneous insulin infusion (CSII) using an insulin pump, which have now been in clinical use for over 40 years. It is possible to achieve significant improvements in glycated hemoglobin (HbAlc) with either MDI or CSII. In the Diabetes Control and Complications trial (DCCT), the intensive group demonstrated major reductions in microvascular complication risk as compared with control [3]. In a subsequent analysis of the intensive group, nearly $40 \%$ were on CSII by the end of the DCCT. For those in the intensive group who only used CSII $(n=124)$ vs those who only used MDI $(284)$, there was a slight favor towards CSII (final HbAlc of $6.8 \%$ with CSII vs $7.0 \%$ with MDI, $P \leq 0.05$ ) [4]. A metaanalysis comparing MDI versus CSII regimens both utilizing rapid acting insulin analogues performed by Monami et al. demonstrated significant improvement of $\mathrm{HbA} 1 \mathrm{c}$ in comparison with MDI (standardized difference in mean, $-0.3[-0.4 ;-0.1] \% ; P<0.001)$. The authors demonstrated no significant difference in the rate of severe hypoglycemic episodes [5]. Other meta-analyses have shown reduction in hypoglycemia, depending upon the definition used, and when including studies comparing CSII with MDI regimens utilizing regular human insulin $[6,7]$. CSII also offers advantages over MDI in individuals with clinical considerations such as dawn phenomenon, extreme insulin sensitivity, erratic schedules, and needle phobias [8].

Historically physicians detected hyperglycemia by examining urine samples for volume, appearance, and taste. The first commercially available SMBG became available starting in the 1980s and CGM in 1999 [9]. A distinguishing characteristic of CGM is that it measures interstitial fluid (ISF) glucose concentration as opposed to SMBG, which measures capillary blood glucose concentration. Although ISF and plasma blood glucose concentration are highly correlated, there is a well-reported lag between ISF and plasma glucose concentration due to rate limited transport between vascular to intracellular compartments. Studies characterizing this temporal relationship report a delay between 4 and $50 \mathrm{~min}$, with more recent evidence suggesting 7-8 $\mathrm{min}$ in persons with type 1 diabetes (T1D). Large, rapid fluctuations in plasma glucose concentration have been shown to accentuate this time lag [10, 11]. A meta-analysis published in 2013 demonstrated improved $\mathrm{HbAlc}$ with CGM use (mean change $\mathrm{HbAlc}-$ $0.2 \%$ ), but mainly in patients starting sensor augmented pumps at the same time (mean change $\mathrm{HbAlc}-0.7 \%$ ). There was no significant difference as compared with SMBG in regard to episodes of severe hypoglycemia or ketoacidosis [12].
More accurate sensors combined with "smart" predictive algorithms have been shown to attenuate ISF glucose concentration dynamics [13]. Mean absolute relative difference (MARD) is frequently used to assess the accuracy of CGM devices. This measurement is the mean of the absolute difference expressed as a percentage of a reference glucose concentration over many samples [14]. Some of the first commercially available CGMs had a published MARD of $>20 \%$ [15]. The latest generation CGM devices have a MARD $<10 \%$ (Fig. 1, Supplemental Table 1). This is equivalent to or exceeds MARD of some SMBG devices and is felt safe by many sources for non-adjunctive use (i.e., treatment decisions) of CGM $[16,17]$. Other significant advancements include extended sensor life and no required SMBG calibration measurements.

\section{Glucose Metrics}

While HbA1c and SMBG may provide approximations of an individual's glycemic management, glycemic variability and hypoglycemic burden can be less evident $[18,19]$. The Advanced Technologies and Treatments for Diabetes (ATTD) Congress convened an international panel of expert physicians and researchers in February 2017 to define specific metrics for assessing CGM data. The consensus group recommended the use of a standardized single page glucose report of CGM data (Ambulatory Glucose Profile (AGP) developed at the International Diabetes Center in Minneapolis, MN) (Figure 2, Table 1) [20, 21].

The Glucose Management Indicator (GMI) is calculated from average glucose and estimates future lab $\mathrm{HbAlc}$. It is an approximation familiar to most clinicians and patients.

Time in range (TIR) represents the percentage of time measured within a specific glucose threshold. A value between 70 and $180 \mathrm{mg} / \mathrm{dL}$ is a generally accepted target as it has been shown achieving $70 \%$ of the values within this range achieves a HbA1c of approximately $7.0 \%$ [22]. TIR has additionally been correlated with reduction in microvascular complications [23]. Time spent with glucose < $70 \mathrm{mg} / \mathrm{dL}$ is a surrogate for hypoglycemic burden. This threshold is sufficiently low to recommend treatment with a fast-acting carbohydrate and or adjustment of glucoselowering therapy [24].

Standard deviation (SD) and coefficient of variation $(\% \mathrm{CV})$ are measures of glycemic variability. Some controversy exists as to the importance of glycemic variability as a clinical target, but it has also been correlated with development of microvascular complications [25-27]. Glycemic variability has additionally been associated with increased risk of hypoglycemia, patient satisfaction, and quality of life measures [28-31]. 


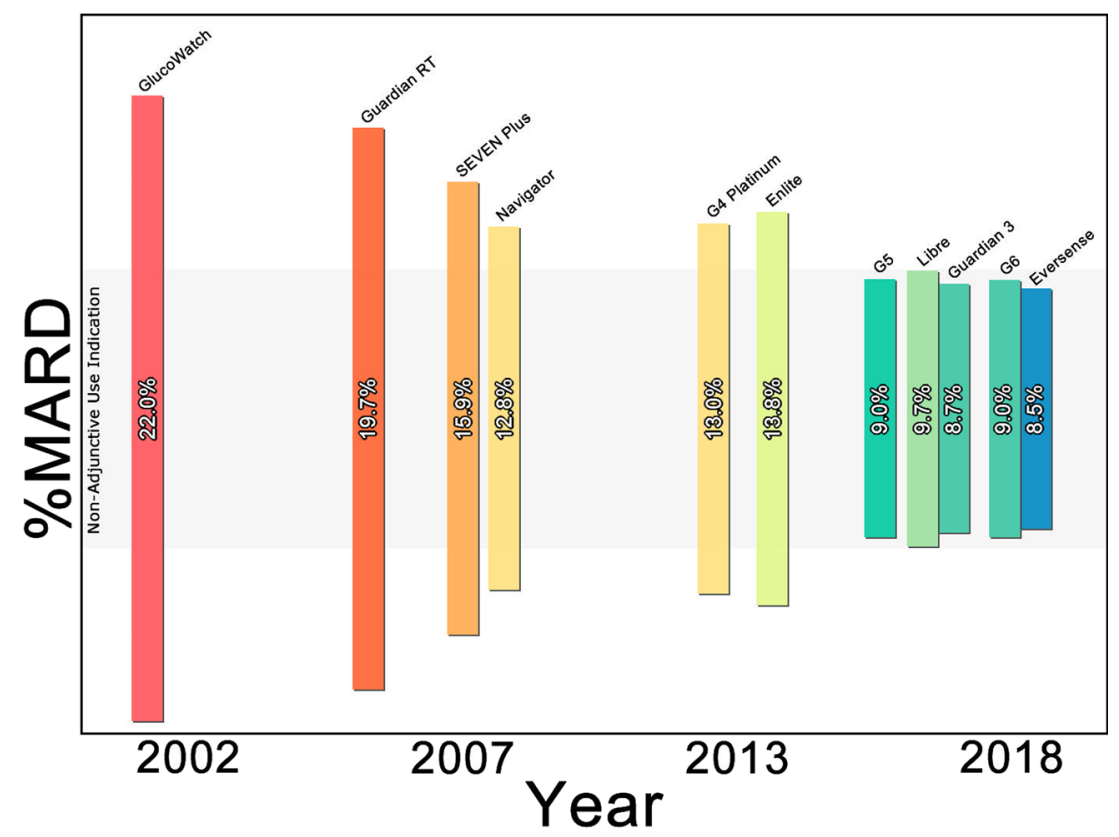

Fig. 1 Device \%MARD vs year commercially available

\section{Recently Published Data Comparing SMBG with CGM}

Recent studies of CGM vs SMBG associate CGM use with improved glycemic variability as measured by $\% \mathrm{CV}$ and time spent with glucose $<70 \mathrm{mg} / \mathrm{dL}$ as compared with SMBG (Figure 3). Not all are associated with statistically significant improvement in $\mathrm{HbAlc}$, which could be explained by low baseline $\mathrm{HbAlc}$ at study entry, reduction in hypoglycemia, and reductions in glucose variability not reflected in the $\mathrm{HbAlc}$ average.

The GOLD study enrolled 161 participants with T1D on MDI therapy and baseline HbA1c of $8.6 \%$ in a randomized cross-over study to either CGM or SMBG first. Treatment periods were 26 weeks each with 17 -week washout periods between assignments. CGM use was associated with statistically significant improved $\mathrm{HbA1c}$ by $-0.4 \%(P<0.001)$. CGM use was also associated with reductions in time spent with glucose $<70 \mathrm{mg} / \mathrm{dL}$ during the day by $40 \%$, evening by $48 \%(P<0.001)$, and $\% \mathrm{CV} 37 \%$ vs $40 \%$ (difference $-3 \%$ (5 to $-2 \%) P<0.001)[32,33]$.

The DIAMOND study enrolled 158 participants with T1D on MDI therapy and baseline $\mathrm{HbA} 1 \mathrm{c}$ of $8.6 \%$, and randomized them to either CGM or SMBG. The treatment period was 24 weeks. CGM use was associated with statistically significant improved $\mathrm{HbAlc}$ by $-0.6 \%(P<0.001)$. CGM use was also associated with statistically significant reductions in time spent with glucose $<70 \mathrm{mg} / \mathrm{dL}$ by $46 \%(P=0.002)$ and $\% \mathrm{CV}$ $38 \%$ vs $42 \%$ (difference $-4 \%(-6$ to $-2 \%)(P<0.001)$ [34].

The IMPACT study enrolled 328 participants with T1D and baseline $\mathrm{HbAlc} 6.7 \%$ in a randomized trial of SMBG vs CGM. Seventy percent of participants utilized MDI and 30\% CSII.
The treatment period was 6 months. CGM use was not associated with statistically significant improved $\mathrm{HbAlc}$. CGM use was associated with statistically significant reductions in time spent $<70 \mathrm{mg} / \mathrm{dL}$ by $38 \%(P<0.0001)$ and $\% \mathrm{CV} 37.6 \%$ vs $41.8 \%$ (difference $-4.4 \%(-5.0$ to $-3.8 \%)(P<0.0001)$ [35].

\section{Recently Published Data Comparing SMBG with CGM in Individuals with Hypoglycemia Unawareness}

The IN CONTROL study enrolled 52 participants with T1D and baseline $\mathrm{HbA} 1 \mathrm{c}$ of $7.5 \%$ in a randomized cross-over trial to either SMBG or CGM first. Insulin delivery methods included 44\% CSII and 56\% MDI. Inclusion criteria were notable for hypoglycemia unawareness. Treatment periods were 16 weeks with a 12 week of washout period. No significant difference in HbAlc was observed. CGM use was associated with statistically significant reductions in time spent with glucose $<70 \mathrm{mg} /$ dL by $40 \%(P<0.001)$ and $\%$ CV $39.5 \%$ vs $46.3 \%$ (difference $-6.7 \%(-8.0$ to $-5.5 \%) P<0.0001)$. It is also worth mentioning the authors did not demonstrate a difference for time spent in a normoglycemic state between MDI and CSII [36].

The HypoDE study enrolled 149 participants with T1D and baseline $\mathrm{HbA} 1 \mathrm{c} 7.4 \%$ in a randomized trial of SMBG vs CGM. Inclusion criteria were notable for MDI therapy and hypoglycemia unawareness. The treatment period was 22 weeks. CGM was not associated with a statistically significant reduction in $\mathrm{HbAlc}$. CGM was associated with statistically significant reductions in time spent with glucose < $70 \mathrm{mg} / \mathrm{dL}$ by $75 \%(P<0.0001)$ and $\% \mathrm{CV} 41.1 \%$ vs $34.1 \%$ (difference $-6.2 \%(-7.5$ to $-5.0 \%) P<0.0001)$ [37]. 
captūrAGP ${ }^{\circledR}$ Name

\begin{tabular}{lll} 
15 Feb 2018 - 01 Mar 2018 & 14.5 days \\
\% Time CGM is Active & $70.6 \%$ \\
\hline Average Glucose & $156 \mathrm{mg} / \mathrm{dL}$ \\
\hline Glucose Management Indicator (GMI) & $7.0 \%$ \\
\hline Coefficient of Variation (CV) & $46 \%$ \\
\hline
\end{tabular}
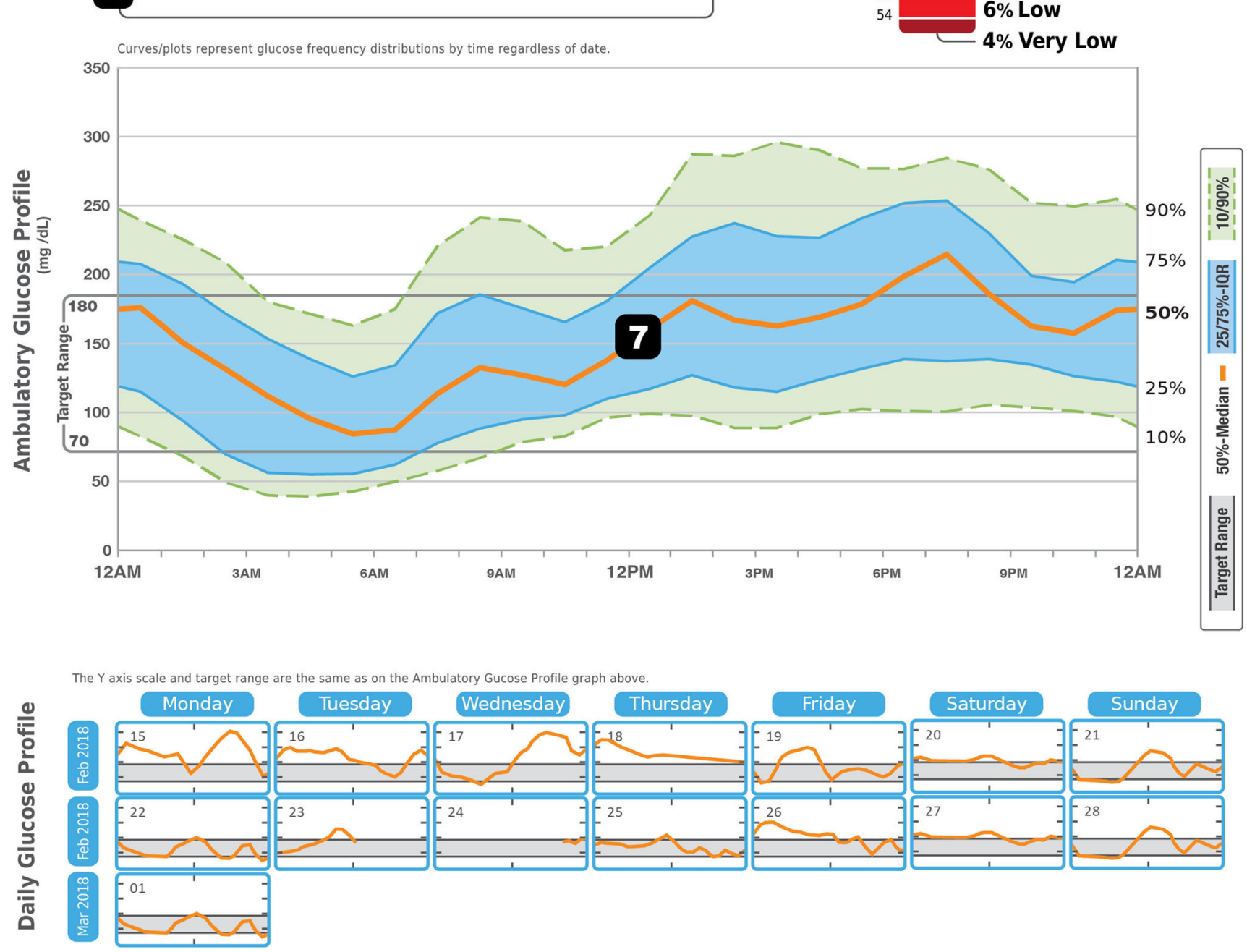

U.S. D773,478 S, Patents Pending - HealthPartners Institute dba International Diabetes Center - All Rights Reserved.

Fig. 2 Representative Ambulatory Glucose Profile. (@2019 International Diabetes Center at Park Nicollet, Minneapolis, MN. Used with permission. See AGPreport.org for more information)

\section{Recently Published Clinical Research Comparing CGM with CSII}

There is some limited literature directly comparing CGM vs CSII.

A retrospective review of 396 newly diagnosed patients with T1D utilizing CSII and MDI was performed analyzing $\mathrm{HbAlc}$, among other outcomes, in CGM users and non-CGM users over 2.5 years of follow-up. CGM users had a lower HbA1c regardless of insulin delivery method. Specifically, the MDI + CGM group had significantly lower HbA1c than the CSII only group $(7.7 \% \pm 0.2 \%$ vs $8.7 \% \pm 0.07 \%, P<0.0001)$ [38].

A similar cross-sectional analysis of 17,731 registry participants from the Type 1 Diabetes Exchange also showed 
Table 1 Definitions of CGM metrics present within the Ambulatory Glucose Profile

\begin{tabular}{|c|c|c|c|c|}
\hline Key & Measure & Definition & Formula & Variables \\
\hline 1 & $\begin{array}{l}\text { Percent time CGM } \\
\text { active }\end{array}$ & $\begin{array}{l}\text { Hours the CGM collected data, divided by } \\
\text { number of hours in the report }\end{array}$ & $\mathrm{ti} / t$ & $\mathrm{ti}=$ time cgm data collected, $t=$ time in the report \\
\hline 2 & Average glucose & $\begin{array}{l}\text { All glucose values added together, divided } \\
\text { by number of readings }\end{array}$ & $\sum \mathrm{xi} / k$ & $\begin{array}{l}\mathrm{xi}=\text { individual glucose values, } k=\text { number of } \\
\text { observations }\end{array}$ \\
\hline 3 & $\begin{array}{l}\text { Glucose Management } \\
\text { Indicator }\end{array}$ & $\begin{array}{l}\text { Calculated from average glucose; estimates } \\
\text { future lab } \mathrm{HbA} 1 \mathrm{C}\end{array}$ & $3.31+0.02392 \overline{\mathrm{x}}$ & $\bar{x}=$ average glucose in $\mathrm{mg} / \mathrm{dL}$ \\
\hline 4 & Coefficient of variation & $\begin{array}{l}\text { How far apart (wide) glucose values are; } \\
\text { ideally a low number }\end{array}$ & $s / \bar{x}$ & $s=$ standard deviation, $\bar{x}=$ average glucose \\
\hline 5 & Standard deviation & $\begin{array}{l}\text { How far values are from the average; } \\
\text { ideally a low number }\end{array}$ & $\sum \mathrm{xi}-\bar{x} / 2 k-1$ & $\begin{array}{l}\mathrm{xi}=\text { individual glucose values, } \bar{x}=\text { average } \\
\text { glucose }, k=\text { number of observations }\end{array}$ \\
\hline 6 & Time in range & $\begin{array}{l}\text { Hours the CGM measures glucose within a } \\
\text { specified range, divided by number of } \\
\text { hours in the report }\end{array}$ & $\operatorname{tr} / t$ & $\operatorname{tr}=$ time in range, $t=$ time in the report \\
\hline 7 & $\begin{array}{l}\text { Ambulatory Glucose } \\
\text { Profile }\end{array}$ & $\begin{array}{l}\text { Daily glucose profiles are combined to make } \\
\text { a } 1 \text { day (24-h) picture. Ideally, lines would } \\
\text { stay within gray shaded area (target range) }\end{array}$ & & $\begin{array}{l}\text { Orange: median (middle) line where half of the } \\
\text { glucose values are above and half are below; } \\
\text { ideally, the orange line is mostly flat and inside } \\
\text { the gray shaded area, Blue: area between blue } \\
\text { lines shows } 50 \% \text { of the glucose values; ideally, } \\
\text { space between is narrow, Green: } 10 \% \text { of values } \\
\text { are above ( } 90 \% \text { top line) and } 10 \% \text { are below } \\
\text { (10\% bottom line); ideally, the closer the green } \\
\text { lines are to the gray shaded area, the better }\end{array}$ \\
\hline
\end{tabular}

improved $\mathrm{HbA} 1 \mathrm{c}$ in CGM users regardless of insulin delivery method. Specifically, the MDI + CGM group had a significantly lower $\mathrm{HbA} 1 \mathrm{c}$ than CSII alone users $(7.7 \pm 1.1 \%$ vs 8.3 $\pm 1.5 \%$, adjusted $P<0.001$ ) [39].

In a 28-week follow-on trial to the DIAMOND study, 75 participants utilizing CGM with baseline HbA1c 7.6\% were randomly assigned to either continue MDI or transition to CSII. CSII users demonstrated increased time in range 70$180 \mathrm{mg} / \mathrm{dL}$ vs MDI (791 vs $741 \mathrm{~min}$ per day, $P=0.01$ ).
However, CSII users also demonstrated increased time spent with glucose $<70 \mathrm{mg} / \mathrm{dL}$ vs MDI (49 vs 32 min per week, $P=$ $0.0001)$. The $\% \mathrm{CV}$ was $39 \%$ in the CSII group and $37 \%$ in the MDI group, which did not achieve statistical significance $(P=$ $0.25)[40 \bullet]$.

The COMISAIR study enrolled 65 participants with baseline $\mathrm{HbA} 1 \mathrm{c} 8.3 \%$ randomized to either MDI $+\mathrm{SMBG}(n=$ $18), \mathrm{CSII}+\mathrm{SMBG}(n=20), \mathrm{MDI}+\mathrm{CGM}(n=12)$, or sensoraugmented pumps (SAP) $(n=15)$. Participants were followed

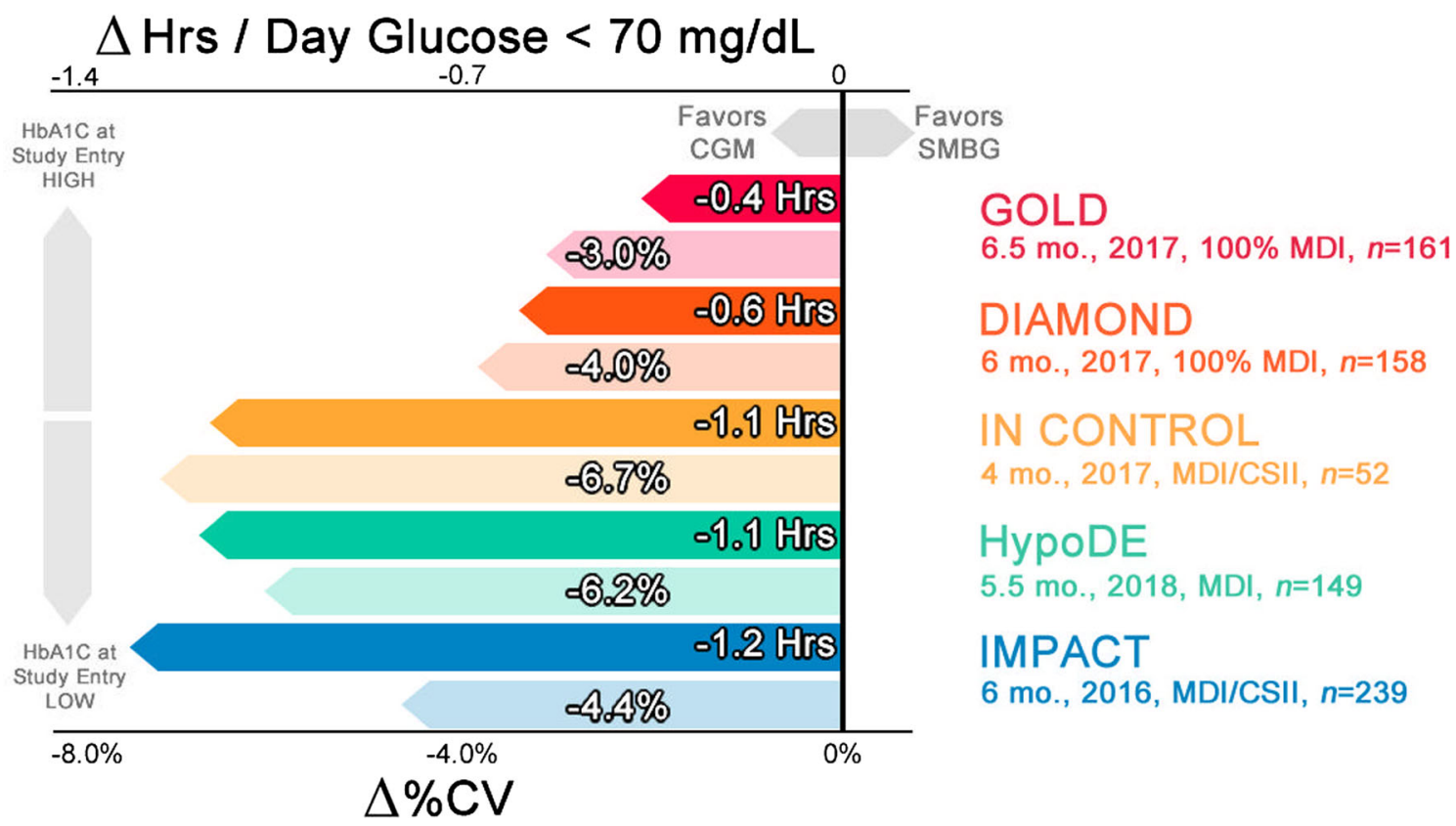

Fig. 3 Summary of recently published CGM trials demonstrating reduction in time spent with glucose $<70 \mathrm{mg} / \mathrm{dL}$ and \%CV as compared with SMBG 


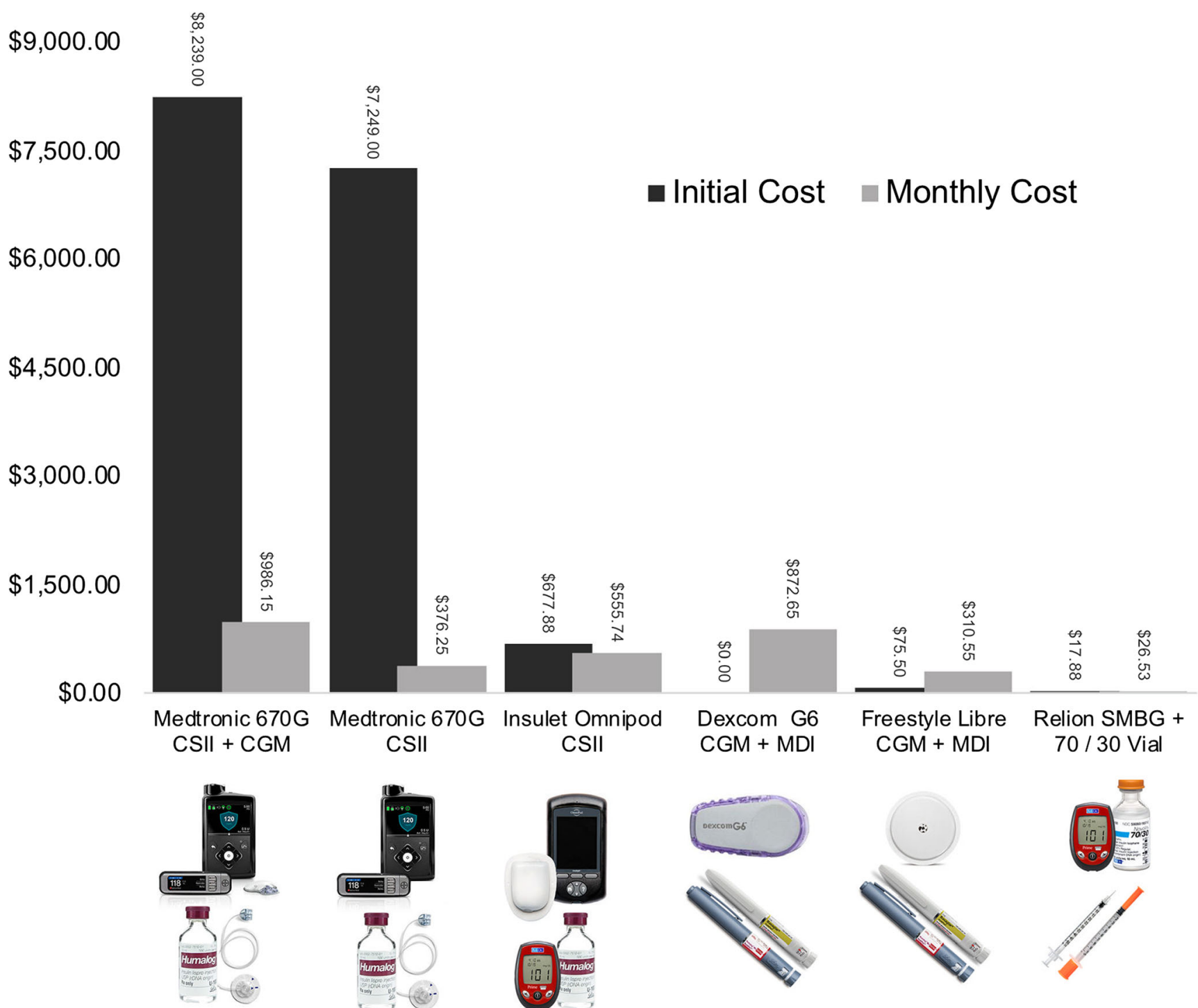

Fig. 4 Estimated Initial and ongoing out-of-pocket costs of various diabetes treatment approaches. Refer to Supplemental Table 2 for pricing appendix

for 1-year at 3-month intervals. The SAP and MDI + CGM groups demonstrated comparable outcomes with statistically significant reduction in both $\mathrm{HbA1c}$ ( $7.1 \%$ at end of study) and glycemic variability (total standard deviation at study entry $4.0 \mathrm{mmol} / \mathrm{L}$ vs $3.0 \mathrm{mmol} / \mathrm{L}$ at study completion; $P<0.0001)$. The CSII + SMBG group also demonstrated improved $\mathrm{HbA} 1 \mathrm{c} 7.9 \%$ and glycemic variability $(3.9 \mathrm{mmol} / \mathrm{L}$ vs $3.4 \mathrm{mmol} / \mathrm{L}$ ), but the study authors remarked MDI + CGM was "clearly superior" to CSII + SMBG. No significant improvement was noted in any study endpoints by the MDI + SMBG group [41•].

\section{Practical Considerations}

Starting CSII takes on average $2-4 \mathrm{~h}$ of initial patient education [42]. This includes device selection, configuration, canula insertion technique, and appropriate responses to device emergencies. Close follow-up is recommended during transition from MDI to CSII to confirm appropriate insulin dosing. A multi-disciplinary team consisting of an endocrinologist, diabetes educator, and dietician is also typically recommended. In contrast, starting CGM is often complementary to an existing treatment regimen. Patient education is more focused, emphasizing the difference between SMBG and CGM, device selection, configuration, and sensor insertion technique [43].

There is an association between CGM use and improved patient satisfaction and quality of life measures [32-37]. A recent survey of 1040 adolescents and their parents associated CGM use with reduced diabetes-specific emotional distress as compared with MDI alone, CGM + CSII, and CSII alone. The authors also reported CGM use was associated with lower HbA1C compared with MDI alone, CSII alone, and comparable with CGM + CSII. They hypothesized this was due to 
CGM making diabetes management easier with improved detection of hypoglycemia and increased time spent in range [44]. There is a well-established association between hypoglycemia and decreased quality of life scores [45]. Reducing hypoglycemic burden has clinical implications as antecedent hypoglycemia has been shown to impair future hypoglycemia awareness [46]. With improvement in hypoglycemia detection, CGM use has also been associated with recovery of hypoglycemia awareness. However, it should be noted CGM has not been found superior to SMBG in conjunction with structured patient education for recovery of hypoglycemia awareness [37, 47].

CGM has a lower up-front cost as compared with CSII (Figure 4, Supplemental Table 2). This is in large part due to the expense of the insulin pump itself. This cost is amplified by rapid device obsolescence as manufacturers frequently release new models with each incremental feature upgrade. Conversely, many CGMs integrate with patient owned smart devices circumventing the up-front cost of a dedicated receiver. Integration with smart devices enables functions previously only available on insulin pumps. These include hypoglycemia and hyperglycemia alarms, digital log books, carbohydrate counters, and insulin dosing calculators. Transfer of CGM data via the internet to cloud-based storage also facilitates telemedicine and family alerts.

\section{Conclusion}

The centennial anniversary of the discovery of insulin will be reached in 2021 [1]. There have been many subsequent breakthroughs translated into routine clinical practice greatly improving the care of persons with T1D [48]. Advancements have been accelerated by validation that lower HbA1c with frequent SMBG is associated with delay or prevention of diabetes-related microvascular complications [3, 49]. The newest generation of CGMs offers improved accuracy and ease of use. They provide a more complete glycemic profile for patients and providers to make treatment decisions. Although earlier research focused on the addition of CGM to CSII, recent evidence demonstrates CGM use is associated with improved outcomes irrespective of insulin delivery method. Practical considerations such as patient satisfaction, initial education, and up-front costs of CGM are also frequently superior to CSII. For these reasons, we advocate for CGM as the initial technology recommendation. If additional technology is needed to improve time in target range or to further reduce time in hypoglycemic range, insulin pump therapy should be discussed with consideration for a hybrid closed loop system to achieve these goals [50-52].
Funding Amy B. Criego reports grants from NIH/NIDDK (UC4DK108611). Richard M. Bergenstal reports his technology research is partly funded by NIH/NIDDK (UC4DK108611).

\section{Compliance with Ethical Standards}

Conflict of Interest Christopher T. Martin reports consulting fees and stock from MicroOptx Inc. In addition, he is co-inventor of patent US20180333085A1 "Aqueous humor monitoring devices and methods" pending to MicroOptx Inc.

Amy B. Criego reports grants and other from Abbott Diabetes Care, other from Eli Lilly, grants from Medtronic, other from Senseonics, and grants from DexCom.

Anders L. Carlson is employed by HealthPartners Institute/Park Nicollet Health Services and they have contracts with Abbott, Medtronic, Dexcom, Novo Nordisk, Sanofi, and Insulet for his services as a research investigator and/or consultant. No personal income from any of these services goes to Anders L. Carlson.

Richard M. Bergenstal has received research support, consulted, or has been on the scientific advisory board for Abbott Diabetes Care, DexCom, Hygieia, Johnson \& Johnson, Eli Lilly, Medtronic, Novo Nordisk, Onduo, Roche, Sanofi, Senseonics, and United Healthcare. His employer, non-profit HealthPartners Institute, contracts for his services and no personal income goes to Richard M. Bergenstal.

Human and Animal Rights and Informed Consent This article does not contain any studies with human or animal subjects performed by any of the authors.

Open Access This article is distributed under the terms of the Creative Commons Attribution 4.0 International License (http:// creativecommons.org/licenses/by/4.0/), which permits unrestricted use, distribution, and reproduction in any medium, provided you give appropriate credit to the original author(s) and the source, provide a link to the Creative Commons license, and indicate if changes were made.

\section{References}

Papers of particular interest, published recently, have been highlighted as:

- Of importance

1. Rosenfeld L. Insulin: discovery and controversy. Clin Chem. 2002;48(12):2270-88.

2. Hirsch IB. Insulin analogues. N Engl J Med. 2005;352(2):174-83.

3. Nathan DM, Genuth S, Lachin J, et al. The effect of intensive treatment of diabetes on the development and progression of long-term complications in insulin-dependent diabetes mellitus. $\mathrm{N}$ Engl J Med. 1993;329(14):977-86.

4. Implementation of treatment protocols in the Diabetes Control and Complications Trial. Diabetes Care. 1995;18(3):361-376.

5. Monami M, Lamanna C, Marchionni N, Mannucci E. Continuous subcutaneous insulin infusion versus multiple daily insulin injections in type 1 diabetes: a meta-analysis. Acta Diabetol. 2010;47(Suppl 1):77-81.

6. Colquitt J, Royle P, Waugh N. Are analogue insulins better than soluble in continuous subcutaneous insulin infusion? Results of a meta-analysis. Diabet Med. 2003;20(10):863-6.

7. Pickup JC, Sutton AJ. Severe hypoglycaemia and glycaemic control in type 1 diabetes: meta-analysis of multiple daily insulin 
injections compared with continuous subcutaneous insulin infusion. Diabet Med. 2008;25(7):765-74.

8. Bode BW, Sabbah HT, Gross TM, Fredrickson LP, Davidson PC. Diabetes management in the new millennium using insulin pump therapy. Diabetes Metab Res Rev. 2002;18(Suppl 1):S14-20.

9. Olczuk D, Priefer R. A history of continuous glucose monitors (CGMs) in self-monitoring of diabetes mellitus. Diabetes Metab Syndr. 2018;12(2):181-7.

10. Basu A, Dube S, Slama M, Errazuriz I, Amezcua JC, Kudva YC, et al. Time lag of glucose from intravascular to interstitial compartment in humans. Diabetes. 2013;62(12):4083-7.

11. Basu A, Dube S, Veettil S, Slama M, Kudva YC, Peyser T, et al. Time lag of glucose from intravascular to interstitial compartment in type 1 diabetes. J Diabetes Sci Technol. 2015;9(1):63-8.

12. Langendam M, Luijf YM, Hooft L, Devries JH, Mudde AH, Scholten RJ. Continuous glucose monitoring systems for type 1 diabetes mellitus. Cochrane Database Syst Rev. 2012;1:CD008101.

13. Facchinetti A. Continuous glucose monitoring sensors: past, present and future algorithmic challenges. Sensors (Basel). 2016;16(12).

14. Reiterer F, Polterauer P, Schoemaker M, Schmelzeisen-Redecker G, Freckmann G, Heinemann L, et al. Significance and reliability of MARD for the accuracy of CGM systems. J Diabetes Sci Technol. 2017;11(1):59-67.

15. Tierney MJ, Tamada JA, Potts RO, Jovanovic L, Garg S, Team CR. Clinical evaluation of the GlucoWatch biographer: a continual, noninvasive glucose monitor for patients with diabetes. Biosens Bioelectron. 2001;16(9-12):621-9.

16. Kovatchev BP, Patek SD, Ortiz EA, Breton MD. Assessing sensor accuracy for non-adjunct use of continuous glucose monitoring. Diabetes Technol Ther. 2015;17(3):177-86.

17. Aleppo G, Ruedy KJ, Riddlesworth TD, Kruger DF, Peters AL, Hirsch I, et al. REPLACE-BG: a randomized trial comparing continuous glucose monitoring with and without routine blood glucose monitoring in adults with well-controlled type 1 diabetes. Diabetes Care. 2017;40(4):538-45.

18. Frier BM. Hypoglycaemia in diabetes mellitus: epidemiology and clinical implications. Nat Rev Endocrinol. 2014;10(12):711-22.

19. Beck RW, Connor CG, Mullen DM, Wesley DM, Bergenstal RM. The fallacy of average: how using HbA. Diabetes Care. 2017;40(8): 994-9.

20. Danne T, Nimri R, Battelino T, Bergenstal RM, Close KL, DeVries $\mathrm{JH}$, et al. International consensus on use of continuous glucose monitoring. Diabetes Care. 2017;40(12):1631-40.

21. Bergenstal RM, Ahmann AJ, Bailey T, Beck RW, Bissen J, Buckingham B, et al. Recommendations for standardizing glucose reporting and analysis to optimize clinical decision making in diabetes: the ambulatory glucose profile. J Diabetes Sci Technol. 2013;7(2):562-78

22. Beck RW, Bergenstal RM, Cheng P, et al. The relationships between time in range, hyperglycemia metrics, and HbAlc. J Diabetes Sci Technol. 2019;1932296818822496.

23. Beck RW, Bergenstal RM, Riddlesworth TD, Kollman C, Li Z, Brown AS, et al. Validation of time in range as an outcome measure for diabetes clinical trials. Diabetes Care. 2019;42(3):400-5.

24. Association AD. 6. Glycemic targets. Diabetes Care. 2018;41(Suppl 1):S55-64.

25. Hirsch IB. Glycemic variability and diabetes complications: does it matter? Of course it does! Diabetes Care. 2015;38(8):1610-4.

26. Bergenstal RM. Glycemic variability and diabetes complications: does it matter? Simply put, there are better glycemic markers! Diabetes Care. 2015;38(8):1615-21.

27. Smith-Palmer J, Brändle M, Trevisan R, Orsini Federici M, Liabat $\mathrm{S}$, Valentine $\mathrm{W}$. Assessment of the association between glycemic variability and diabetes-related complications in type 1 and type 2 diabetes. Diabetes Res Clin Pract. 2014;105(3):273-84.
28. Qu Y, Jacober SJ, Zhang Q, Wolka LL, DeVries JH. Rate of hypoglycemia in insulin-treated patients with type 2 diabetes can be predicted from glycemic variability data. Diabetes Technol Ther. 2012;14(11):1008-12.

29. Testa MA, Gill J, Su M, Turner RR, Blonde L, Simonson DC. Comparative effectiveness of basal-bolus versus premix analog insulin on glycemic variability and patient-centered outcomes during insulin intensification in type 1 and type 2 diabetes: a randomized, controlled, crossover trial. J Clin Endocrinol Metab. 2012;97(10): 3504-14.

30. Ayano-Takahara S, Ikeda K, Fujimoto S, Hamasaki A, Harashima SI, Toyoda K, et al. Glycemic variability is associated with quality of life and treatment satisfaction in patients with type 1 diabetes. Diabetes Care. 2015;38(1):e1-2.

31. Kilpatrick ES, Rigby AS, Goode K, Atkin SL. Relating mean blood glucose and glucose variability to the risk of multiple episodes of hypoglycaemia in type 1 diabetes. Diabetologia. 2007;50(12): 2553-61.

32. Lind M, Polonsky W, Hirsch IB, Heise T, Bolinder J, Dahlqvist S, et al. Continuous glucose monitoring vs conventional therapy for glycemic control in adults with type 1 diabetes treated with multiple daily insulin injections: the GOLD randomized clinical trial. JAMA. 2017;317(4):379-87.

33. Ólafsdóttir AF, Polonsky W, Bolinder J, Hirsch IB, Dahlqvist S, Wedel $\mathrm{H}$, et al. A randomized clinical trial of the effect of continuous glucose monitoring on nocturnal hypoglycemia, daytime hypoglycemia, glycemic variability, and hypoglycemia confidence in persons with type 1 diabetes treated with multiple daily insulin injections (GOLD-3). Diabetes Technol Ther. 2018;20(4):274-84.

34. Beck RW, Riddlesworth T, Ruedy K, Ahmann A, Bergenstal R, Haller $\mathrm{S}$, et al. Effect of continuous glucose monitoring on glycemic control in adults with type 1 diabetes using insulin injections: the DIAMOND randomized clinical trial. JAMA. 2017;317(4):371-8.

35. Bolinder J, Antuna R, Geelhoed-Duijvestijn P, Kröger J, Weitgasser R. Novel glucose-sensing technology and hypoglycaemia in type 1 diabetes: a multicentre, non-masked, randomised controlled trial. Lancet. 2016;388(10057):2254-63.

36. van Beers CA, DeVries JH, Kleijer SJ, et al. Continuous glucose monitoring for patients with type 1 diabetes and impaired awareness of hypoglycaemia (IN CONTROL): a randomised, open-label, crossover trial. Lancet Diabetes Endocrinol. 2016;4(11):893-902.

37. Heinemann L, Freckmann G, Ehrmann D, Faber-Heinemann G, Guerra S, Waldenmaier D, et al. Real-time continuous glucose monitoring in adults with type 1 diabetes and impaired hypoglycaemia awareness or severe hypoglycaemia treated with multiple daily insulin injections (HypoDE): a multicentre, randomised controlled trial. Lancet. 2018;391(10128):1367-77.

38. Mulinacci G, Alonso GT, Snell-Bergeon JK, Shah VN. Glycemic outcomes with early initiation of continuous glucose monitoring system in recently diagnosed patients with type 1 diabetes. Diabetes Technol Ther. 2019;21(1):6-10.

39. Foster NC, Miller KM, Tamborlane WV, Bergenstal RM, Beck RW, Network TDEC. Continuous glucose monitoring in patients with type 1 diabetes using insulin injections. Diabetes Care. 2016;39(6): e81-2.

40. Beck RW, Riddlesworth TD, Ruedy KJ, et al. Effect of initiating use of an insulin pump in adults with type 1 diabetes using multiple daily insulin injections and continuous glucose monitoring (DIAMOND): a multicentre, randomised controlled trial. Lancet Diabetes Endocrinol. 2017;5(9):700-8. Findings from this study suggest mixed results in those utilizing CGM who transition from MDI to CSII. The authors report statistically significant increased time in range, but also time spent in the hypoglycemic range $<70 \mathrm{mg} / \mathrm{dL}$ and no statistically significant improvement in $\% \mathrm{CV}$. 
41. S Šoupal J, Petruželková L, Flekač M, et al. Comparison of different treatment modalities for type 1 diabetes, including sensoraugmented insulin regimens, in 52 weeks of follow-up: a COMISAIR study. Diabetes Technol Ther. 2016;18(9):532-8. Findings from this study suggest CGM + MDI is superior to SMBG + CSII.

42. Bolderman KM, American Diabetes Association. Putting your patients on the pump. 2nd ed. Alexandria, VA: American Diabetes Association; 2013.

43. Peters AL, Ahmann AJ, Battelino T, Evert A, Hirsch IB, Murad $\mathrm{MH}$, et al. Diabetes technology-continuous subcutaneous insulin infusion therapy and continuous glucose monitoring in adults: an Endocrine Society clinical practice guideline. J Clin Endocrinol Metab. 2016;101(11):3922-37.

44. Vesco AT, Jedraszko AM, Garza KP, Weissberg-Benchell J. Continuous glucose monitoring associated with less diabetesspecific emotional distress and lower A1c among adolescents with type 1 diabetes. J Diabetes Sci Technol. 2018;12(4):792-9.

45. Frier BM. How hypoglycaemia can affect the life of a person with diabetes. Diabetes Metab Res Rev. 2008;24(2):87-92.

46. Heller SR, Cryer PE. Reduced neuroendocrine and symptomatic responses to subsequent hypoglycemia after 1 episode of hypoglycemia in nondiabetic humans. Diabetes. 1991;40(2):223-6.

47. Little SA, Speight J, Leelarathna L, Walkinshaw E, Tan HK, Bowes A, et al. Sustained reduction in severe hypoglycemia in adults with type 1 diabetes complicated by impaired awareness of hypoglycemia: two-year follow-up in the HypoCOMPaSS randomized clinical trial. Diabetes Care. 2018;41(8):1600-7.

48. Lung TW, Hayes AJ, Herman WH, Si L, Palmer AJ, Clarke PM. A meta-analysis of the relative risk of mortality for type 1 diabetes patients compared to the general population: exploring temporal changes in relative mortality. PLoS One. 2014;9(11):e113635.

49. Intensive blood-glucose control with sulphonylureas or insulin compared with conventional treatment and risk of complications in patients with type 2 diabetes (UKPDS 33). UK Prospective Diabetes Study (UKPDS) Group. Lancet. 1998;352(9131):837853.

50. Bergenstal RM, Tamborlane WV, Ahmann A, Buse JB, Dailey G, Davis SN, et al. Effectiveness of sensor-augmented insulinpump therapy in type 1 diabetes. N Engl J Med. 2010;363(4): 311-20.

51. Bergenstal RM, Klonoff DC, Garg SK, Bode BW, Meredith M, Slover RH, et al. Threshold-based insulin-pump interruption for reduction of hypoglycemia. N Engl J Med. 2013;369(3): 224-32.

52. Garg SK, Weinzimer SA, Tamborlane WV, Buckingham BA, Bode BW, Bailey TS, et al. Glucose outcomes with the in-home use of a hybrid closed-loop insulin delivery system in adolescents and adults with type 1 diabetes. Diabetes Technol Ther. 2017;19(3):155-63.

Publisher's Note Springer Nature remains neutral with regard to jurisdictional claims in published maps and institutional affiliations. 